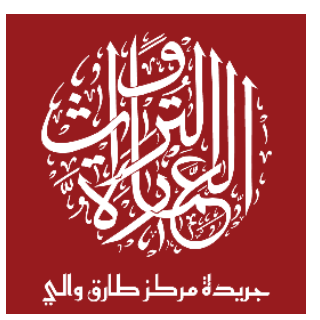

جريدة مركز طارق والي العمارة والتراث العدد 13 - 22 فبراير 2022 الاستشراق .... الأمس واليوم والغد

\title{
المستشرقون وعمران القاهرة
}

استقر اء تأثير الحركة الاستشر اقية في عمران القاهرة

نهاية القرن التاسع عشر وحتى منتصف القرن العشرين

مركز طارق والي العمارة والتراث

10.47288/TWCJ.2022.V07.ISS13.P02 (DOI) رابط التعريف الرقمي

الملخص

يقدم هذا المقال تعريف ملخص بالمشروع البحثي " المستشرقون وعمران القاهرة ، استقراء تأثير الحركة الاستشراقية في عمران القاهرة - نهاية القرن التاسع عشر وحتى منتصف القرن العشرين " و الذي اطلقه مركز

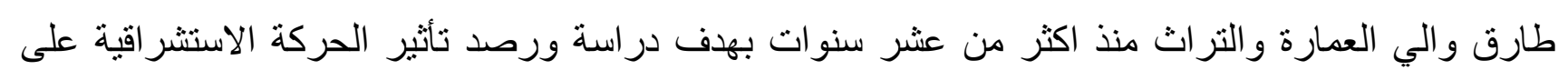

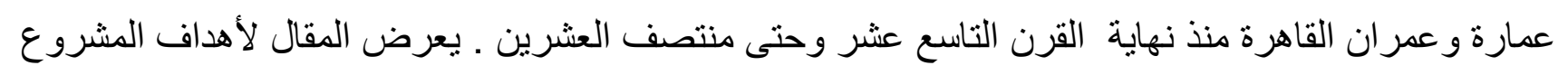
و أهم محاوره و إصدار انه.

\section{الكلمات الدلالية}

القاهرة ، الاستشراق ، المستشرقين ، القرن التاسع عشر ، القرن العشرين ، عمران ، عمارة ، توثيق التراث

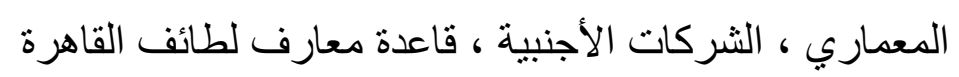


المستشرقون وعمران القاهرة

استقراء ثتأثير الحركة الاستثر اقية في عمران القاهرة

نهاية القرن التاسع عشر وحتى منتصف القرن العشرين

قامت العلاقة بين الغرب والشرق منذ التاريخ القديم والوسيط وحتى التاريخ الحديث على قوى الجذب و الثد ، على الكر والفر .. إنه سحر الثرق المكان والتاريخ ، عالم متوهج بروعة الإبداع والخلود أجتذب الغرب أدباء وفلاسفة وشعر اء ورحالة وفنانين ، فأقبلو مشوقين إلى تلك الحضارة .. ومن جهة أخرى كانت ثروات الشرق وكنوزه منبع لا ينضب وموقع متفرد أجنذب الداني والقاصي من مغامرين سياسيين و عسكريين تسار عو ا إلى هذا المعين طامعين في الثروة و السلطة .. هكذا كانت علاقة الغرب بالثرق علاقة تسلطية و أعجاب من طرف لحساب الآخر بهدف السيطرة والاحتو اء الفكري أو التحكم والاستغلال المادي سواء قديماً أو حديثاً .. . وقد أدت الحملة الفرنسية في نهاية القرن الثامن عثر إلى ازدياد الاهتمام بالثرق ، وتجلى ذلك في قوة الاتجاه الإستشر اقي الجديد الذي تز عمه " سير وليام جونز " فكثر النقل المباثر عن اللغات الثرقية ، وبعد أن كان الثرق مجرد وسيلة أو ذريعة لغاية ، أصبح موضو عاً في حد ذاته يتم تناوله ودر استه بطريقة عقلانية و علمية .

وبمرور الوقت امتد اثر الحركة الإستشر اقية ليتعدى الدراسات الثرقية إلى التدخلات المباشرة وغير المباشرة التي تركت بصماتها الواضحة على عمران القاهرة ، فخرج المستشرقون من دور المشاهد لصورة القاهرة إلى دور الفاعل في رسم صورة عمران القاهرة ، على المستوى الفكري والمهني داخل وخارج المؤسسات الرسمية المسئولة عن إدارة وتتظيم العمران والحفاظ على التراث ، كما احتكروا مجالات التصميم المعماري والداخلي و التشيبيد والاستثمار العقاري وكذلك توثيق وثرميم التراث المعماري و إعادة صياغة وتقديم مظاهر هذا التراث من وجهة نظر هم ـ بل وتعدى دور هم المجال المهني إلى المجالات الفكرية والمعرفية بل والتعليم أيضا. وبالرغم من مظاهر التحديث في هذه المرحلة إلا إنه من الضروري تحري الدقة عند التعامل بالتحليل العلمي المحايد و الموضو عي للغايات و المفاهيم لتلك التجارب التحديثية لعمر ان مصر وحاضرتها القاهرة وبنيتها المؤسسية للدولة والمجتمع و إدارتها للعمران، بكل ما يحمله المجتمع لهذا العمران من موروث متداخل أحياناً ومتنافر أحياناً أخرى .. وليس بالضرورة هنا نقصد إننا نتبنى هذه المواقف ولكننا على العكس نرصدها لاستكثاف خفايا تلك

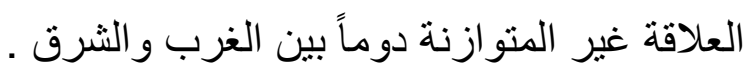

وفي هذا الإطار يكرس مركز طارق و الي العمارة والتراث قطاع من مجهوداته البحثية منذ اكثر من عشر سنوات نحو إعادة استقر اء تلك الظاهرة ، من خلال مشروع بحثي توثيقي مستمر بعنوان : المستشرقون و عمران القاهرة 
، ويهدف إلى رصد وتوثيق تأثيرات الحركة الإستشر اقية في القاهرة مع نهاية القرن التاسع عشر وحتى منتصف

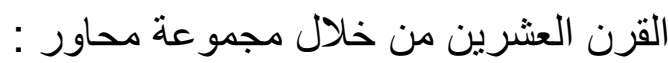
خرائط القاهرة شاهد على العمران

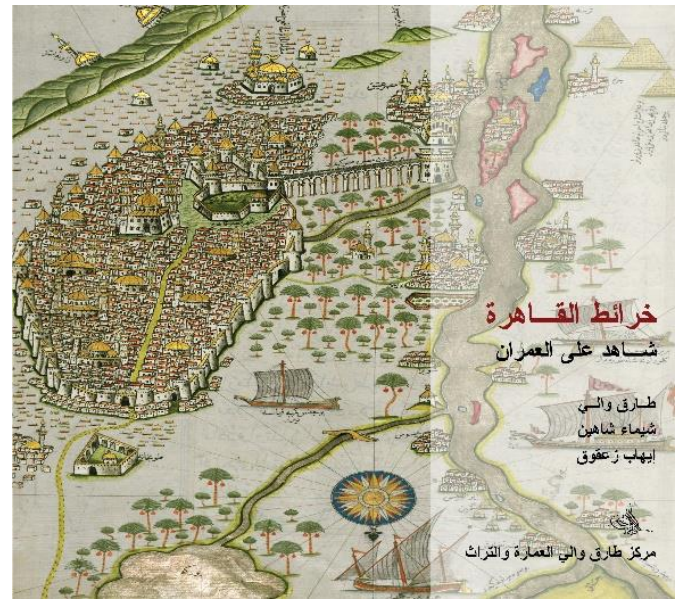

شكل 1 كتاب خرائط القاهرة شاهد على العدران تلعب الخرائط دوراً أساسيا في التعرف على رحلة القاهرة المحروسة وعمرانها، باعتبار أن الذاكرة المرسومة احدى التعبيرات المصورة لتدوينات التاريخ والمؤرخين والرحالة المكتوبة، فالإنسان والزمان و المكان أبعاد ثلاثية للمنظومة

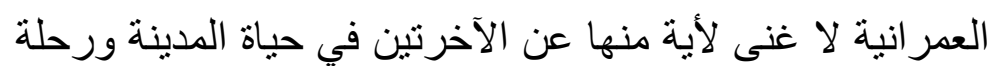

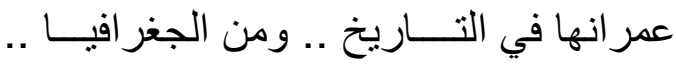
الخريطة هنا وثيقة الجغر افيا ومفردات لغتها كما أن الكلمة المكتوبة وثيقة التاريخ ولغتهـهـ فالخريطة في هذا المقام تصوير ما حدث أو الحادث أو المثكة ولثنه حدوثه توثيق لحقيقة و اقعة أو مدكنة الوقوع لعمر ان الدينة وحياة الإنسان و المجتمع

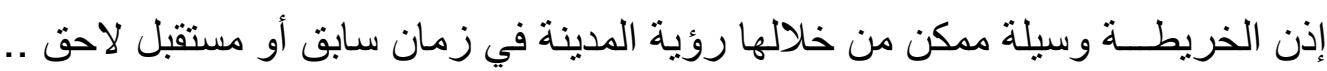

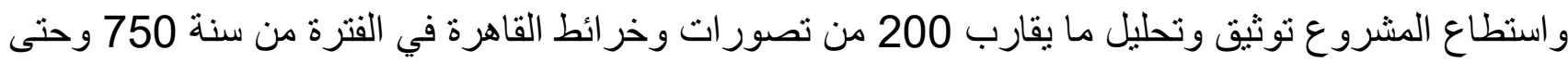
1972 ، وكذلك دراسة وتوثيق التطور التقني لإنتاج الخرائط عبر العصور المختلفة ونطورات علم الكارنو غر افيا و الكورو غر افيا ، وقد نتج عن المرحلة الأولى من المشروع إصدار خاص ضمن مبادرة الكتاب الرقمي المفتوح: خر ائط القاهرة .. شاهد على العمر العندان 
لوحات المستشرقين في القرن التاسع عشر

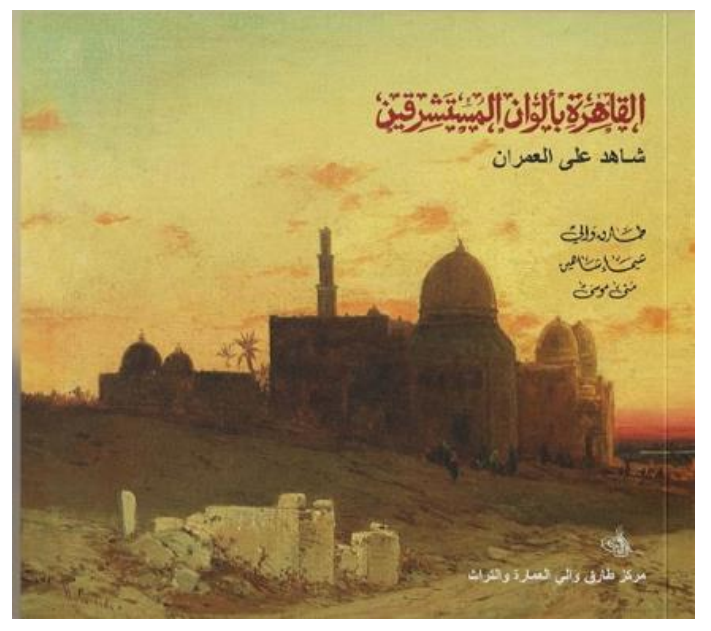

شكل 2 كتاب القاهرة بألو ان المستشرقين

لقد حمل الرحالة و الفنانون المستشرقون جزء من مسئولية توثيق عمران القاهرة وحياة المجتمع لتكون مرجعية مكمله لكتابات المؤرخين ، ولتكون مع غيرها من المرجعيات العلمية و الوثائقية لكل باحث ، ومع هذا الكم من إبداعيات

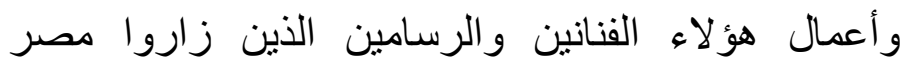
و القاهرة ، تجد تللك الأعمال التي وثقت لتللك المرحلة من رحلة القاهرة وسكانها ، إلا أننا بقدر ما نعتمد عليها كمرجعية

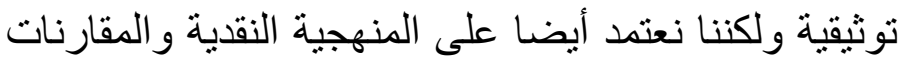
مع المراجع التاريخية الأخرى حيث هنالك من هؤلاء

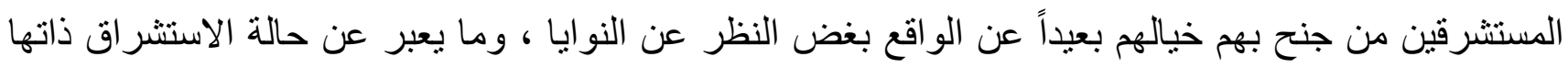
و أغر اضها المعلنة أو الخفية ونخص بالذكر هنا أسماء مجموعة مختارة من هؤلاء المستشرقين ، مجموعة تمثل بهل بقدر الممكن و المتاح لتتويعات الددارس الإستشر اقية المختلفة ، و الممتدة من بدايات القرن التاسع عشر وحتى مطلع القرن العشرين ـ ونهدف في هذا المشروع إلى رصد المكن والمناح من تلك الأعمال مع مر اعاة تدقيقها والتحقق

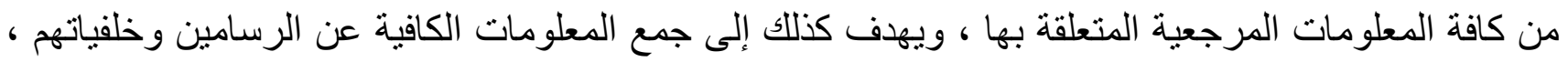

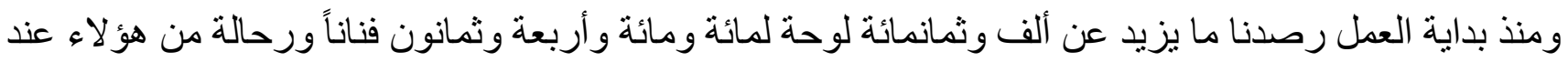
زيارتهم القاهرة خلال تللك المرحلة من الرحلة مثلوا في مجموعهم ورسوماتهم صورة عامة للمدينة ، والمجتمع

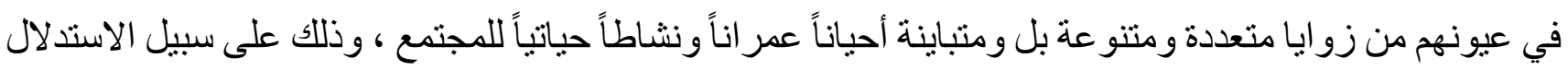

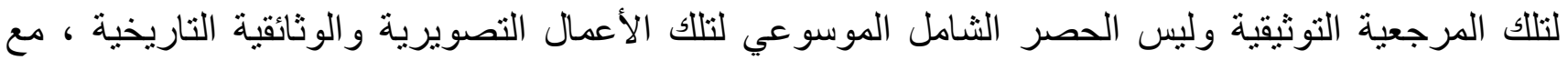
مر اعاتنا التدقيق الموضوعي لتللك الأعمال في مقابل المرجعيات الوثائقية الأخرى المعاصرة و المنزامنة لهؤلاء الفنانين .

و أفرزت المرحلة الأولى من المشروع عن تكوين نواة للأرشيف الرقمي للوحات المستشرقين في القاهرة ، وكذلك عن إنتاج إصدار خاص ضمن مبادرة الكتاب الرقمي المفتوح هو: 


\section{الصور الفوتوغرافية في نهاية القرن التاسع عشر وبداية القرن العشرين}

التقطت أول صورة فوتوغر افية في الثرق ومصر في 4 نوفمبر سنة 1839 بحضور محمد علي بانثا في مدينة

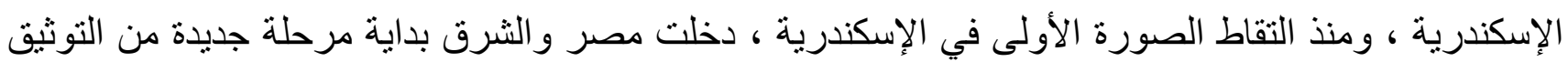
المرئي ، وأخذ مئات المصورين بالتدفق على مصر وسوريا ، و التقطت آلاف الصور للمعابد و الهياكل القديمة الإنية للمدن والقرى ، وصورت عدسات المصورين مختلف المناظر ومظاهر الحياة الاجتماعية .ومنذ منتصف القرن التاسع عشر أخذ المصورين طرق لتصوير خارج ديارهم الأصلية نوجهوا على الفور إلى مصر وفلسطين و إسطنبول ، وفي كثثر من الأحيان كان تأسيس وستوديوهات التصوير التجارية من قبل المقيمين الدائمين سواء داء

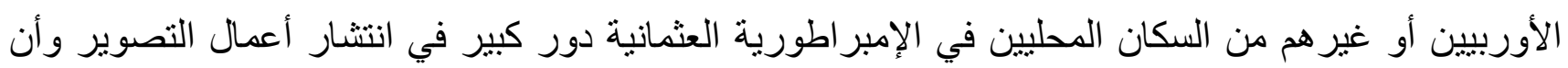

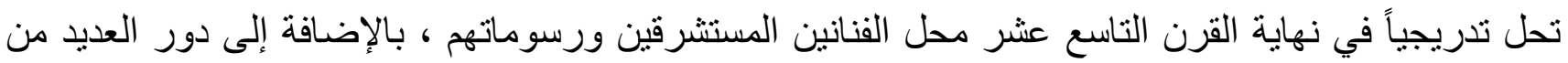

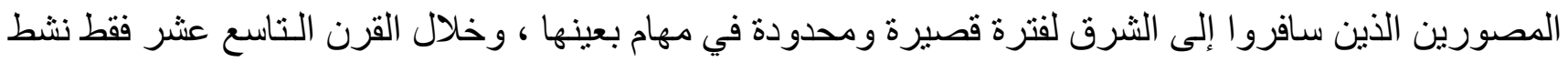

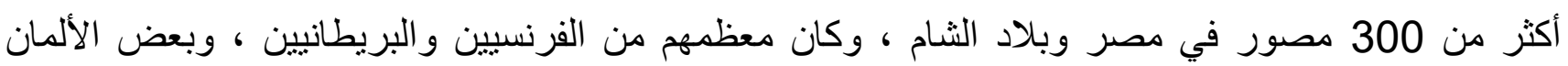

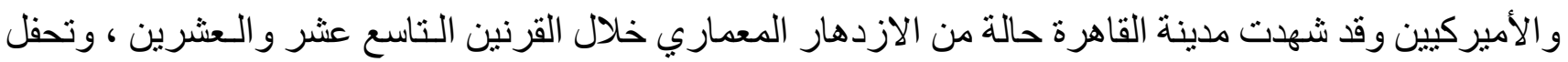
المكتبات المتخصصة والمتاحف بكثير من تلاك المجموعات التي تعكس الوضعية المجتمعية و العمر انية و المعمارية

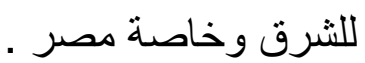

ويهدف المشروع إلى رصد الصور الفوتوغر افية للقاهرة في تللك الفترة ، ومنذ بدء العمل تم رصد حوالي 1300 صورة فوتوغر افية للقاهرة في الفترة بين 1904-1839وكذلك المعلومات الكافية عن ما يقرب من مائة وثثلاثون

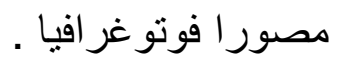

\section{أعمال المعماريين المستشرقين في القاهرة}

تو اترت المشاركات المعمارية والعمرانية الإستشر اقية خلال القرن التاسع عشر واستمرت في القرن العشرين بالرغم من ظهور جيل من المعماريين المصريين الرواد الوطنيين في مواجهة أو مقابلة المعماريين الأوربيين المستشرقين .عموماً قام المعماريون المستشرقون في القرن التاسع عشر الذين زاروا مصر و القاهرة واحتكروا

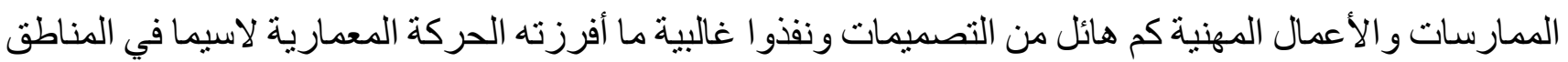
الحضرية وخاصة في مدينة القاهرة ومدينة الإسكندرية ، حين شهدت القاهرة حركة تنمية عمر انية ومعمارية في النصف الثاني من القرن التاسع عثر لاسيما في مناطق النمو العمر اني المستحدثة بالمدينة وأحيائها الجديدة ،

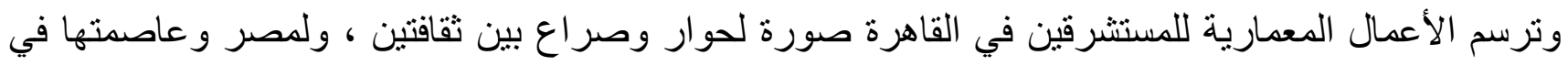
قلب هذا الحو ار وفي مقدمة ذلك الصر اع ، وعمارة القرن التاسع عشر (مرحلة الهيمنة الاستعمارية الفكرية و الثقافية 
المستترة أو العسكرية والسياسية المباشرة) ـ وتقدم صفحة موثقة عن تاريخ ورحلة القاهرة لتلك الجدلية ومدلو لاتها في حياة المدينة و المجتمع .

ويهذف المشروع لتوثيق الأعمال المعمارية للمستثرقين في القاهرة منذ القرن التاسع عشر وحتى منتصف القرن العشرين ، وخلال مسيرة المشروع تم رصد ما يقرب من ثلاثمائة عمل لحو الي مائة معماري ، وقام المركز بتنظيم

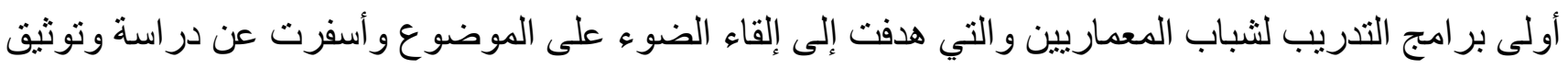

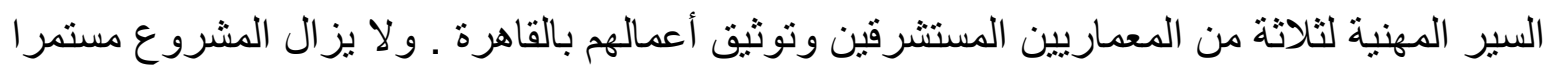
الثركات الأجنبية في مجال الاستثمار العقاري في القاهرة في القرن العشرين

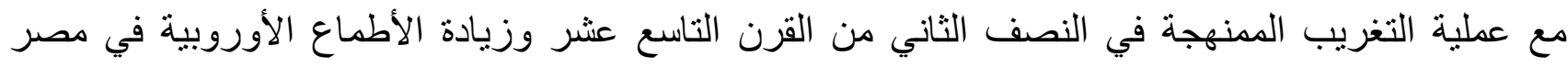

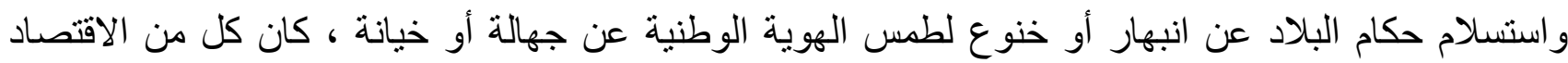

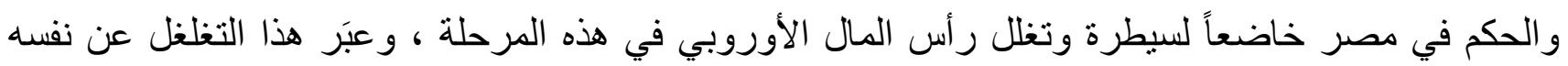

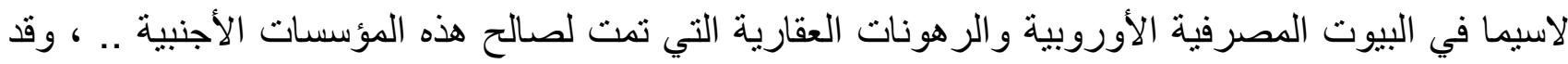

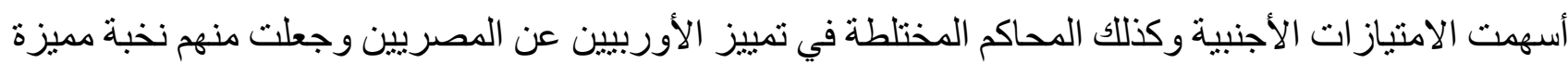

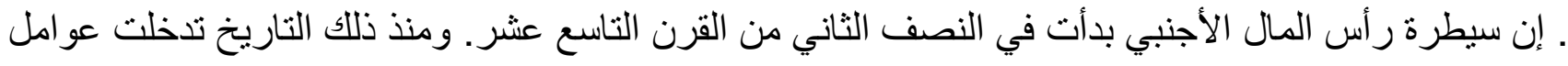

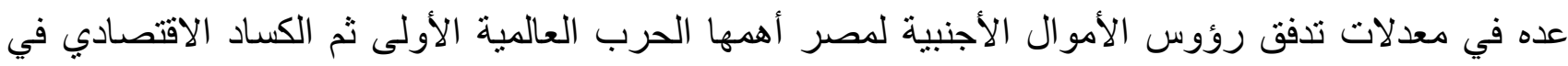

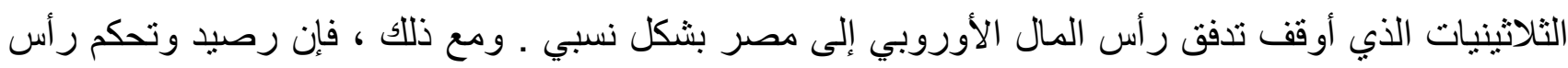

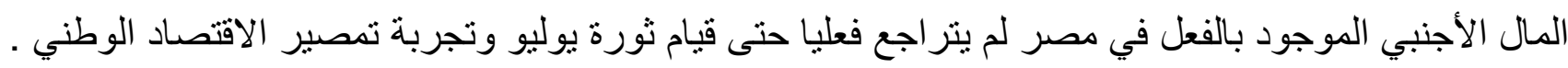

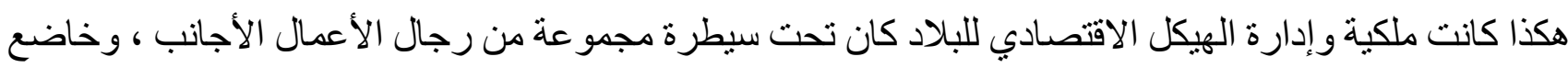
لسيطرة مصالحهم الخاصة ومصالح الدول التي يمثلونها ؛ يثاركهم بنسبة محدودة عدد من رجال الأعمال

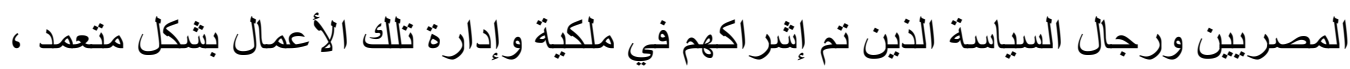
بالرغم من نقص البيانات الدقيقة التي ترصد حجم ونشاط تللك الثركات العاملة في الاستثمار العقاري في مصر مع مطلع القرن العشرين ، إلا أنه يمكن رسم صورة لتللك الثركات من خلال الإحصاءات الرسمية السنوية لوز الترارة

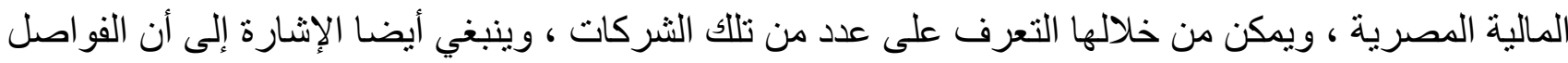

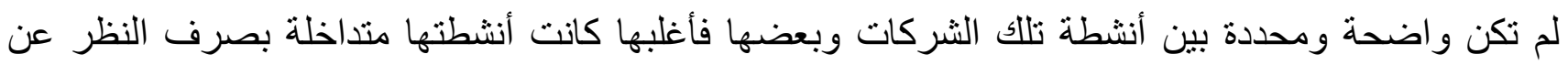
التصنيف الرسمي للثركة ، و عملت أغلبها في شر اء وبيع الأر اضي الحضرية و الزر اعية وتقسيم الأر اضي و إنشاء

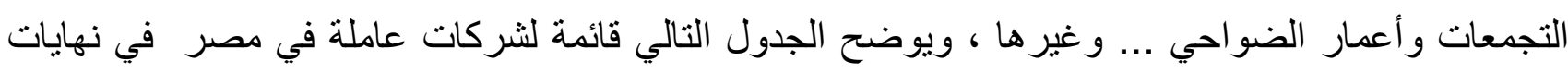
القرن التاسع عشر ومطلع القرن العشرين وهي وعير 


\begin{tabular}{|c|c|c|c|c|}
\hline أنشطة الثركة & الثركية & التأسيس & \multicolumn{2}{|l|}{ 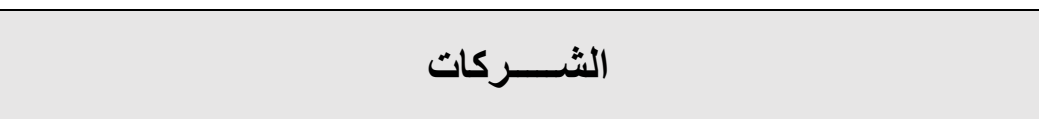 } \\
\hline \multicolumn{5}{|c|}{ 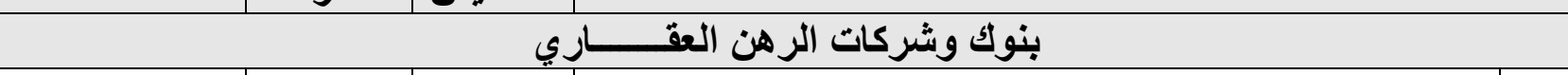 } \\
\hline & & \multirow{2}{*}{1880} & Credit Foncier Egyptian Bank & \multirow[b]{2}{*}{1} \\
\hline & & & بنأك الائتمان العقاري الهصري & \\
\hline & & \multirow{2}{*}{1880} & Land and Mortgage Company of Egypt & \multirow{2}{*}{2} \\
\hline & & & شركة الأر اضي الرهن العقاري المصرية & \\
\hline & & \multirow{2}{*}{1902} & The Agricultural Bank of Egypt & \multirow[b]{2}{*}{3} \\
\hline & & & البنك الزر اعي المصري & \\
\hline & & \multirow{2}{*}{1903} & Caisse Hypothecaire d'E' gypte & \multirow{2}{*}{4} \\
\hline & & & صندوق الرهن العقاري بمصر & \\
\hline & & \multirow{2}{*}{1905} & Land Bank of Egypt & \multirow{2}{*}{5} \\
\hline & & & البناك العقاري المصري & \\
\hline & & \multirow[t]{2}{*}{1908} & $\begin{array}{c}\text { Credit Hypothecaire Agricola et Urbain' } \\
\text { d'Eqvpte Bank }\end{array}$ & \multirow{2}{*}{6} \\
\hline & & & بنك الائتمان و الر هن العقاري الزر اعي والحضري مصر & \\
\hline & & \multirow{2}{*}{1908} & Mortgage Company of Egypt & \multirow{2}{*}{7} \\
\hline & & & شركة الرهن العقاري المصرية & \\
\hline & & \multirow{3}{*}{1910} & Banque Hypothecaire Franco- & \multirow{3}{*}{8} \\
\hline & & & E'gyptienne & \\
\hline & & & البنك الفرنسي المصري للرهون العقارية & \\
\hline & & \multirow{2}{*}{1910} & Credit Foncier d'Orient Bank & \multirow{2}{*}{9} \\
\hline & & & بنك الائتمان العقاري بالثرق & \\
\hline & & \multirow{2}{*}{1911} & Caisse Auxiliaire Fonciere & \multirow{2}{*}{10} \\
\hline & & & صندوق المساعدة العقارية & \\
\hline & & \multirow{2}{*}{1911} & Egyptische Hypotheken Bank & \multirow{2}{*}{11} \\
\hline & & & بنأك القروض العقارية المصري & \\
\hline \multicolumn{5}{|c|}{ شـركات الار اضي الحضريـــــــــة } \\
\hline & \multirow{3}{*}{ فرنسية } & \multirow{3}{*}{1874} & Societe Immobiliere D A Alexandrie & \\
\hline & & & Company & 12 \\
\hline & & & شركة تعمير الاسكندرية & \\
\hline & & & St Mark's Buildings Association Company & \\
\hline & مصرية & 1874 & Ltd & 13 \\
\hline & & & شركة سان مارك المحدودة للبناء & \\
\hline & & & Societe Anonyme D'un Immeuble D'Egypt & 11 \\
\hline & مصريه & 1881 & الثركة المحدودة لمباني مصر & 14 \\
\hline & & & Societe Anonyme Egyptienne d'un & \\
\hline & & 1889 & Immeuble sis rue Cherif pacha (Alexandria) & 15 \\
\hline & & & الثركة المصرية لمباني شارع شريف بانشا بالاسكندرية & \\
\hline & 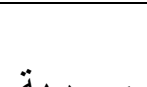 & 1001 & Societe Anonyme D'un Immeuble De & 10 \\
\hline & مصرية & 1894 & الثركة المصرى لمباني الابر اهيمية و الرملة & 16 \\
\hline
\end{tabular}




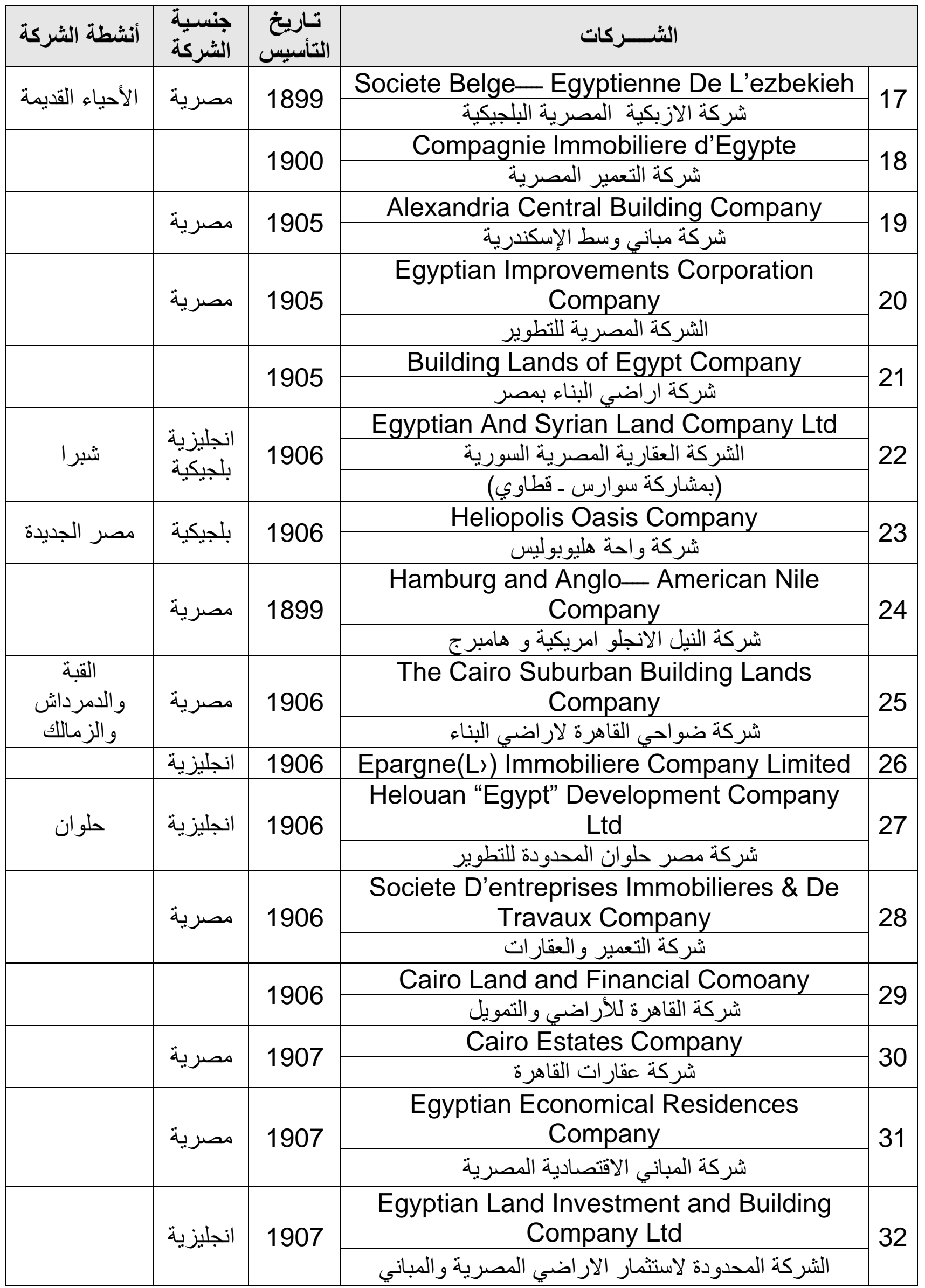




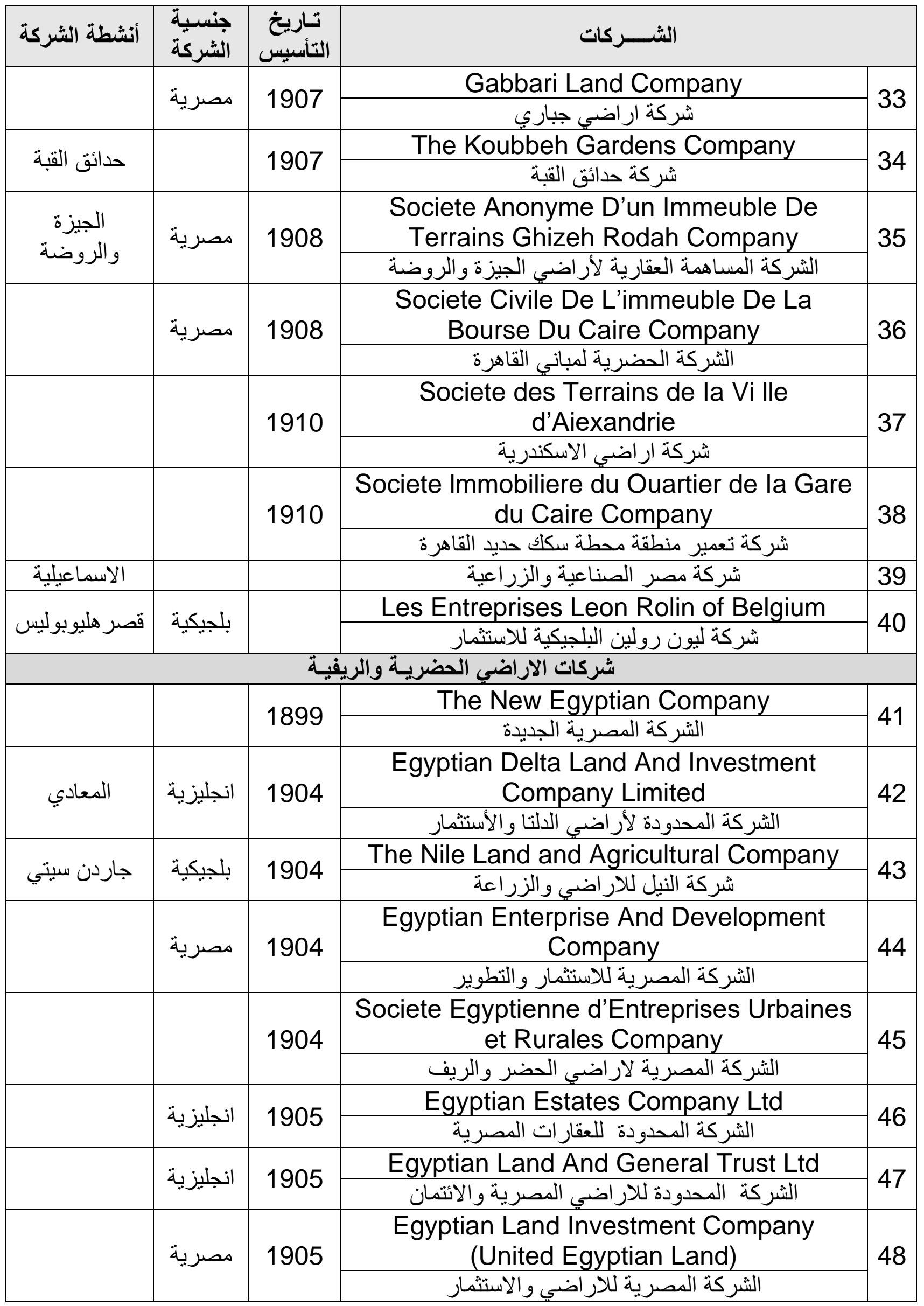




\begin{tabular}{|c|c|c|c|c|}
\hline أنشطة الثركة & جنسية & التأسيس & \multicolumn{2}{|l|}{ الثــــركات } \\
\hline & & \multirow{2}{*}{1905} & $\begin{array}{c}\text { The Anglo_- Egyptian Land Allotment } \\
\text { Company }\end{array}$ & \multirow{2}{*}{49} \\
\hline & & & الثركة الأنجلو المصرية لتخصيص الأراضي & \\
\hline & \multirow{2}{*}{ 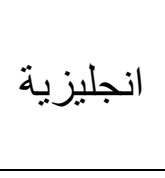 } & \multirow{2}{*}{1906} & $\begin{array}{c}\text { Amlak Syndicate Ltd. (Anglo — American } \\
\text { Nile Company) }\end{array}$ & \multirow{2}{*}{50} \\
\hline & & & نقابة الاملاك المحدودة (شركة النيل الانجلو امريكية) & \\
\hline & \multirow{2}{*}{ انجليزية } & \multirow{2}{*}{1906} & United Egyptian Lands Company Ltd & \multirow{2}{*}{51} \\
\hline & & & الثركة المصرية المتحدة للار اضي & \\
\hline & & \multirow{2}{*}{1906} & Anglo_- Belgian Company of Egypt & \multirow{2}{*}{52} \\
\hline & & & الثركة الأنجلو البلجيكية المصرية & \\
\hline & & \multirow{2}{*}{1906} & United Egyptian Lands Company & \multirow{2}{*}{53} \\
\hline & & & الار اضي المصرية المتحدة & \\
\hline & \multirow{3}{*}{ انجليزية } & \multirow{3}{*}{1907} & City And Agricultural Lands Of Egypt & \multirow{3}{*}{54} \\
\hline & & & الثركة المحدودة لار اضي المدن والار اضي الزر اعية & \\
\hline & & & Favntian Trancactinnc Comnany Itd & \\
\hline & \multirow{2}{*}{ 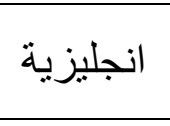 } & \multirow{2}{*}{1907} & Egyptian Transactions Company Ltd & \multirow{2}{*}{55} \\
\hline & & & الثركة المحدودة للتحويلات المصرية & \\
\hline & \multirow{3}{*}{ 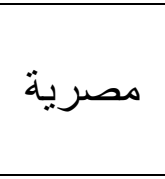 } & \multirow{3}{*}{1907} & Societe De Bien_F Fonds Urbains \& & \multirow{3}{*}{56} \\
\hline & & & Ruraux Company & \\
\hline & & & شركة الار اضي الحضرية و الريفية الجيدة & \\
\hline & \multirow{2}{*}{ مصرية اية } & \multirow{2}{*}{1907} & Sudan Land And Commercial Company & \multirow{2}{*}{58} \\
\hline & & & شركة السودان للار اضي و التجارة & \\
\hline & & \multirow{2}{*}{1909} & Sidi Salem Company of Egypt & \multirow{2}{*}{59} \\
\hline & & & شركة سيدي سالم المصرية & \\
\hline & & 1910 & Nile Land and Agricultural Company & 60 \\
\hline & & טוצו & شركة النيل للار اضي و الزر اعة & 100 \\
\hline & & 1011 & The Egyptian Agricultural Company & 61 \\
\hline & & וזוקו & الثركة الزر اعية المصرية & 101 \\
\hline & & & Union Corporation of Egypt Company & 62 \\
\hline & & & شركة الاتحاد مصر & 02 \\
\hline & & & شــــات القنـــــــــادق & \\
\hline & انحلنان & 1897 & Egyptian Hotels Company Ltd & 63 \\
\hline & الجليرية & 1891 & الشركة المحدودة للفنادق المصرية & b3 \\
\hline & مصرية & & George Nungovich Egyptian Hotels & \\
\hline و وادارة الفنادق & - & 1899 & & 64 \\
\hline & سويسرية & & شتركة فنادق مصر الكبرى ـ تتنارلز بهلر & \\
\hline & مصر بة & 1900 & Compagnie Immobiliere D’Egypt Company & 65 \\
\hline & & & شركة تعمير مصر & (0) \\
\hline
\end{tabular}




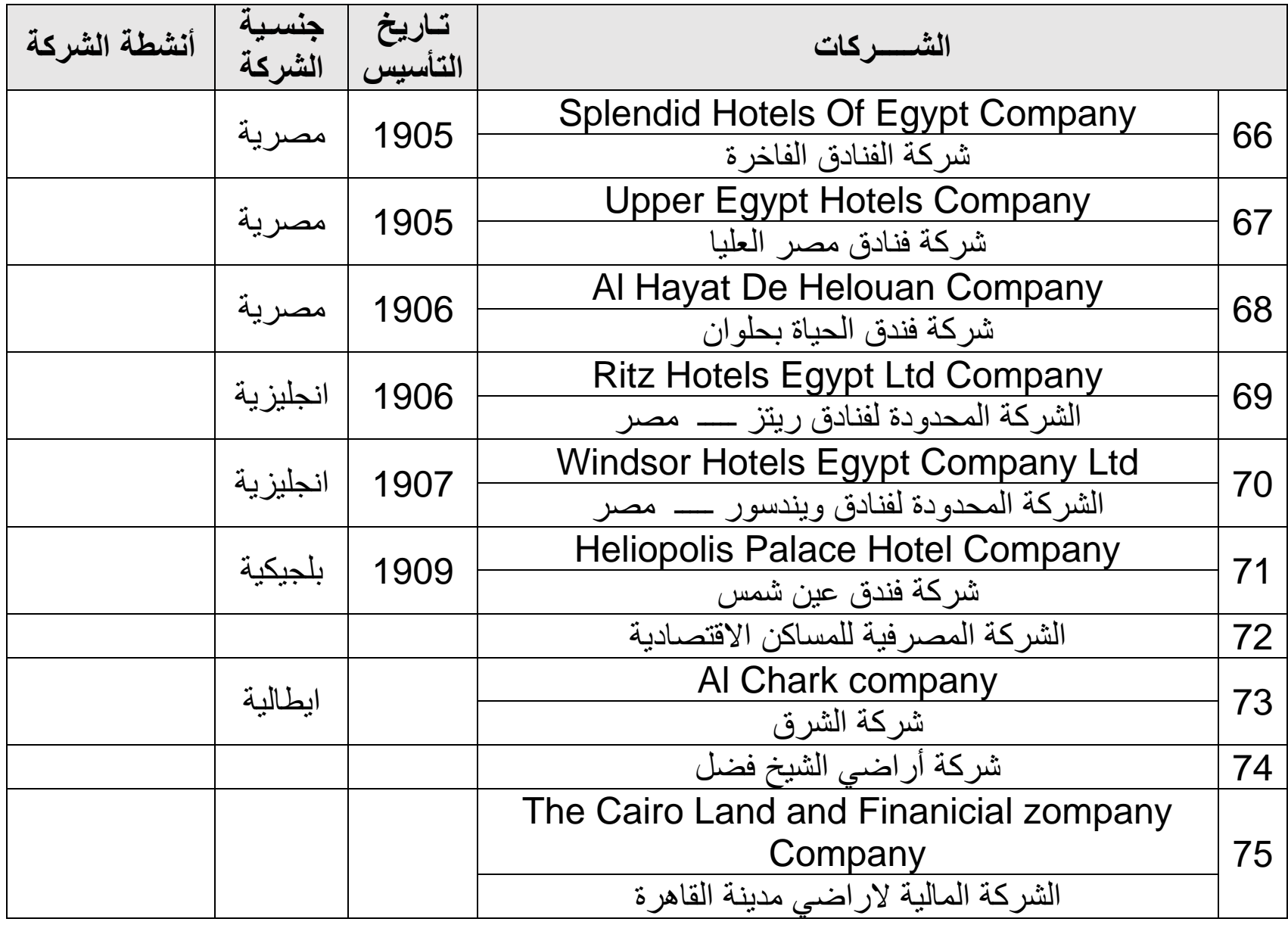

أعتمد توسع عمر ان مدينة القاهرة سواء شرق النيل أو إلى الغرب من النهر على استغلال الأر اضي الفضاء التي

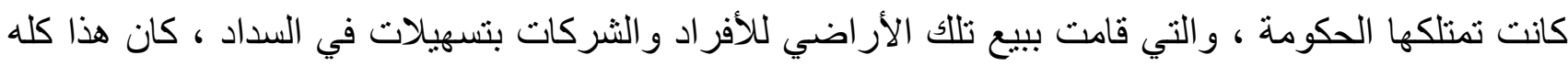

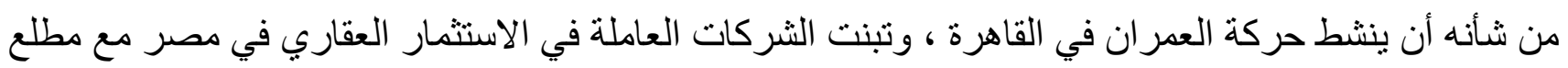
القرن العشرين تقسيم تللك الأر اضي وممارسة أعمال البناء في داخل المدينة في عمر ان أحياء جديدة مستحدثة

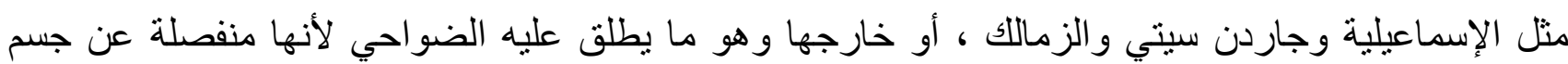
المدينة .

ويستهدف المشروع رصد ودر اسة وتوثيق أنشطة هذه الثركات و المناطق التي خضعت لتلاك الحركة الإستشر اقية في الاستثمار العقاري ، و هي الأراضي التي ضاربت فيها غالبية نللك الثركات ، وظهر هذا النسق من الإعمار في عدة مناطق من القاهرة ، قام المشروع بدر اسة عمارة وعمران عدد من تلالك المناطق منها : م ضاحية مصر الجديدة سنة 1905 (شركة واحة هليوبوليس) م ضاحية شبر اسنة 1906 (الثركة العقارية المصرية السورية) م ض ضاحية القبة سنة 1906 (شركة ضو احي القاهرة لأر اضي البناء) م ضاحية حلوان 1906 سنة (شركة مصر حلوان المحدودة للتطوير) 
O ضاحية الجيزة والعجوزة والدقي (شركة غرب القاهرة) م ضاحية المعادي سنة 1908 (شركة أر اضي الدلتا المصرية) O ضاحية حدائق القبة سنة 1908 (شركة حدائق القبة) م ضاحية الدقي سنة 1918 (شركة أر اضي الجيزة والروضة)

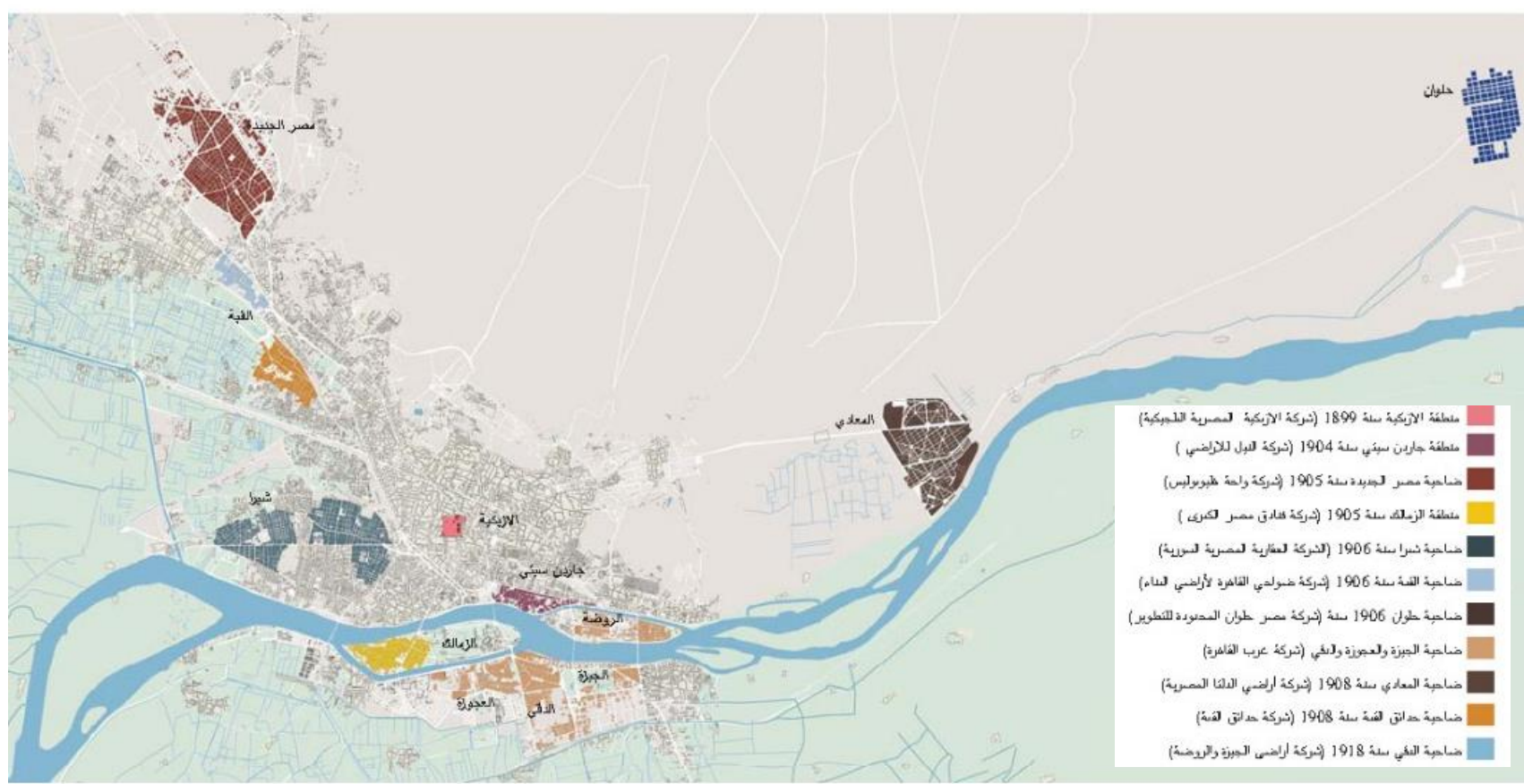

شكل 3 خريطة نوضح أنشطة الشركات الأجنبية العاملة في الاستثمار العقاري في القرن العشرين

و إجمالا ، يهذف المشروع إلى مر اجعة وتتقيح مصادر تاريخنا العمر اني ، و إعادة النظر في الكثير من المنواتر حول تلك الفترة الغنية بالتحو لات .. اسفر المشروع عن مجموعة من الدر اسات الفرعية واسهم كمصادر مرجعية في العمل الموسوعي كتاب : رحلة القاهرة المحروسة من عصر الولاية إلى عصر الاستقلال الوطنى

كما يمثل هذا المشروع احد رو افد تأسيس قاعدة معارف لطائف القاهرة (تحت الإعداد) وتم نشر العديد من نتائج تللك الدر اسات من خلال إصدار اتنا المختلفة على موقع مركز طارق و الي العمارة و التراث ..

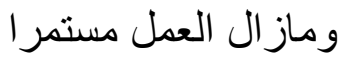

